\title{
Hubungan Pengetahuan Ibu Hamil Tentang Tanda Bahaya Kehamilan Dengan Kejadian Resiko Tinggi (Di BPS Ananda Desa Plosowahyu Kecamatan Lamongan Kabupaten Lamongan )
}

\author{
Fitriana Ikhtiarinawati Fajrin ${ }^{1}$ \\ ${ }^{1}$ Fakultas Kesehatan Prodi D III Kebidanan Universitas Islam Lamongan \\ Email : fitrianaikhtiarinawatifajrin@gmail.com
}

\begin{abstract}
ABSTRAK
Penelitain ini bertujuan untuk mengetahui pengetahuan ibu, mengetahui kejadian resiko tinggi dan menganalisius hubungan pengetahuan ibu hamil tentang tanda bahaya kehamilan dan kejadian resiko tinggi. penelitian adalah deskriptif analitik dengan pendekatan Cross Sectional. Sumber data didapatkan dari seluruh ibu hamil yang melakukan pemeriksaan di BPS Ananda Desa Ploso Wahyu Kecamatan Lamongan Kabupaten Lamongan pada 1 Januari - 1 Mei 2018. Teknik pengumpulan data menggunakan data primer dan data sekunder. Data primer berupa data tentang pengetahuan ibu hamil tentang tanda bahaya kehamilan yang diperoleh dari lembar kuisoner, sedangkan data sekunder berupa tentang kejadian resiko tinggi pada ibu hamil yang diperoleh dari data rekam medik, selanjutnya data dianalisis secara deskriptif dan di uji statistik menggunakan uji chi-Square. Hasil penelitian ini menunjukkan bahwa mayoritas memiliki pengetahuan ibu hamil baik tentang tanda bahaya kehamilan yaitu sebanyak 19 responden (76\%). Mayoritas tidak mengalami resiko tinggi yaitu sebanyak 20 responden $(80 \%)$. Mayoritas responden memiliki berpengetahuan kurang mengalami resiko tinggi yaitu 4 responden $(66,7 \%)$, dan responden yang berpengetahuan baik mayoritas tidak mengalami resiko tinggi yaitu 18 responden $(94,7 \%)$. Dari hasil uji chi-square didapatkan Hasil uji chi-square didapatkan nilai $\chi 2$ hitung $=10,746>5,991$, sehingga H0 ditolak H1 diterima. Simpulan dari penelitian ini terdapat hubungan antara pengetahuan tentang tanda bahaya kehamilan dengan kejadian resiko tinggi.
\end{abstract}

Keywords: Pengetahuan, Tanda bahaya kehamilan, Resiko tinggi 


\begin{abstract}
This research aims to know the knowledge of mother, knowing high risk incident and mengalisius relationship of pregnant woman knowledge about pregnancy danger and high risk event. The research is descriptive analytic with Cross Sectional approach. Source of data obtained from all pregnant women who do the examination in BPS Ananda Village Ploso Wahyu Lamongan District Lamongan regency on January 1 to May 1, 2018. Data collection techniques using primary data and secondary data. Primary data in the form of data about pregnant mother's knowledge about pregnancy signals obtained from sheet kuisoner, while secondary data about high risk incident in pregnant mother obtained from medical record data, then data analyzed descriptively and in statistical test using chiSquare test. The results of this study indicate that the majority have good knowledge of pregnant women about pregnancy alarm signage as much as 19 respondents $(76 \%)$. The majority did not experience high risk as many as 20 respondents $(80 \%)$. The majority of respondents have less knowledge of high risk that is 4 respondents $(66,7 \%)$, and the majority of respondents who have good knowledge do not have high risk that is 18 respondents $(94,7 \%)$. From chi-square test results obtained Chi-square test results obtained value $\chi 2$ count $=10,746>$ 5,991, so $\mathrm{H} 0$ rejected $\mathrm{H} 1$ accepted. Conclusions from this study there is a relationship between knowledge about pregnancy alarm with high risk events.
\end{abstract}

Keywords: Knowledge, Signs of pregnancy danger, High risk

\section{PENDAHULUAN}

Derajat kesehatan merupakan bagian dari pilar utama yang erat kaitannya dengan peningkatan kualitas sumber daya manusia, sehingga dengan derajat kesehatan masyarakat yang tinggi diharapkan dapat tercipta sumber daya manusia yang tangguh, produktif dan mampu bersaing untuk menghadapi semua tantangan yang akan dihadapi dalam pembangunan disegala bidang. Indikator penting dari derajat kesehatan masyarakat khususnya di kabupaten Lamongan salah satunya dilihat dari Angka kematian ibu (AKI) (Dinkes Kabupaten lamongan, 2014).

Menurut Survey Demografi Kesehatan Indonesia (SDKI) tahun 2012 AKI di Indonesia 359 per 100.000 kelahiran hidup
(KEMENKES RI, 2014). Pada tahun 2016, AKI Provinsi Jawa Timur mencapai 91,00 per 100.000 kelahiran hidup (Depkes Prov Jawa Timur 2017), sedangkan (AKI) di kabupaten lamongan sebesar 64 per 100.000 kelahiran hidup (Dinkes Kabupaten Lamongan, 2016). Adapun target Suistainable Development Goal s(SDGs) sampai dengan tahun 2030 adalah mengurangi angka kematian ibu yaitu sebesar 70 per 100.000 kelahiran hidup (Depkes RI, 2015). Menurut direktorat kesehatan, penyebab angka kematian ibu adalah perdarahan, hipertensi, infeksi, partus lama, abortus. Perdarahan merupakan angka tertinggi penyebab kematian ibu sedangkan partus lama merupakan penyebab terendah angka kematian ibu Adapun faktor lainnya 
seperti kondisi ibu hamil dengan penyakit jantung, tuberkolosis atau penyakit lain yang diderita ibu. (KEMENKES RI, 2014). Untuk mencegah terjadinya AKI ibu diperlukan pengelolaan yang baik pada ibu sejak masa kehamilan. Pada masa kehamilan ibu hamil penting untuk memiliki pengetahuan tentang tanda bahaya kehamilan karena apabila tanda-tanda bahaya tersebut diketahui sejak dini, maka penanganan akan lebih cepat. Ibu hamil yang memiliki pengetahuan yang lebih dapat mengetahui tentang resiko tinggi kehamilan yang terjadi sehingga ibu akan berfikir untuk menentukan sikap dan berperilaku untuk mencegah, menghindari atau mengatasi masalah resiko kehamilan (Yulanda, 2014). setiap ibu hamil perlu diberikan penyuluhan tentang tanda-tanda bahaya dalam kehamilan, dan meminta ibu agar segera meminta pertolongan pada tenaga kesehatan apabila mengalami salah satu atau lebih dari tanda bahaya kehamilan tersebut (Fajrin, 2017).

Berdasarkan hasil survey awal di BPS Ananda Desa Plosowahyu Kecamatan Lamongan Kabupaten Lamongan pada Desember 2017 dari 5 ibu hamil didapatkan 1 responden (20 \%) mengalami resiko tinggi dan memiliki pengetahuan rendah tentang tanda bahaya kehamilan, sedangkan 5 responden $(80 \%)$ tidak mengalami resiko tinggi dan memiliki pengetahuan yang baik tentang tanda bahaya kehamilan. pengetahuan ibu hamil tentang tanda bahaya kehamilan di dipengaruhi oleh usia, pendidikan, pekerjaan, persepsi, dan sumber informasi (Notoatmodjo, 2010) Upaya dalam menurunkan kejadian resiko kehamilan adalah pengenalan adanya resiko tinggi pada ibu hamil yang dilakukan melalui skrining/deteksi dini adanya faktor resiko secara pro/aktif pada semua ibu hamil, sedini mungkin dilakukan pada awal kehamilan oleh petugas kesehatan atau non kesehatan yang terlatih di masyarakat, misalnya ibu-ibu PKK, ibu hamil sendiri, suami atau keluarga. Kegiatan skrining antenatal, merupakan langkah awal dari pemeliharaan kesehatan ibu hamil dan termasuk salah satu upaya antisipasi untuk mencegah terjadinya kematian ibu (Rochjati, 2003).

\section{METODE}

Dalam penelitian ini, desain penelitian adalah deskriptif analitik dengan pendekatan Cross Sectional. Sumber data didapatkan dari seluruh ibu hamil yang melakukan pemeriksaan di BPS Ananda Desa Ploso Wahyu Kecamatan Lamongan Kabupaten Lamongan pada bulan 1 Januari - 1 Mei 2018. Teknik pengumpulan data menggunakan data primer dan data sekunder. Data primer berupa data tentang pengetahuan ibu hamil tentang tanda bahaya kehamilan yang diperoleh dari lembar kuisoner, sedangkan data sekunder berupa tentang kejadian resiko tinggi pada ibu hamil yang diperoleh dari data rekam medik, selanjutnya data dianalisis secara deskriptif dan di uji statistik menggunakan uji chi-Square. 


\section{HASIL DAN PEMBAHASAN}

\section{HASIL}

1. Data Data Umum Karakteristik Responden

Tabel 1. Distribusi Frekuensi berdasarkan data umum karakteristik respoden di BPS Ananda Desa Plosowahyu Kecamatan Lamongan Kabupaten Lamongan

\begin{tabular}{|c|c|c|c|}
\hline No. & $\begin{array}{l}\text { Data Umum Karakteristik } \\
\text { responden }\end{array}$ & Frekuensi & Prosentase $(\%)$ \\
\hline \multirow[t]{4}{*}{1} & Usia & & \\
\hline & $<20$ tahun & 4 & $16 \%$ \\
\hline & 20-35 tahun & 15 & $60 \%$ \\
\hline & $>35$ tahun & 6 & $24 \%$ \\
\hline \multirow[t]{4}{*}{2.} & Pendidikan & & \\
\hline & Pendidikan Dasar (SD/SMP) & 3 & $12 \%$ \\
\hline & Pendidikan Menengah (SMA) & 14 & $56 \%$ \\
\hline & Pendidikan Tinggi (Diploma, S1, S2) & 8 & $32 \%$ \\
\hline \multirow[t]{3}{*}{3.} & Pekerjaan & & \\
\hline & Bekerja & 16 & $64 \%$ \\
\hline & Tidak Bekerja & 9 & $36 \%$ \\
\hline \multirow[t]{4}{*}{4.} & Kehamilan ke & & \\
\hline & 1 & 7 & $28 \%$ \\
\hline & $2-4$ & 13 & $52 \%$ \\
\hline & $>4$ & 5 & $20 \%$ \\
\hline
\end{tabular}

Sumber: Data Primer

Berdasarkan Tabel 1, dapat diketahui mayoritas responden berusia 20-35 tahun yaitu sebanyak 15 responden $(60 \%)$, mayoritas berpendidikan menengah (SMA) yaitu sebanyak
14 responden (56\%), mayoritas bekerja sebagai karyawan/wiraswasta sebanyak 16 responden $(64 \%)$ dan mayoritas merupakan kehamilan ke (2-4) sebanyak 52 responden (52\%).

2. Data Tingkat Pengetahuan Ibu tentang Tanda Bahaya Kehamilan

Tabel 2. Distribusi Frekuensi berdasarkan Tingkat Pengetahuan Ibu tentang Tanda Bahaya Kehamilan di BPS Ananda Desa Plosowahyu Kecamatan Lamongan Kabupaten Lamongan

\begin{tabular}{clcc}
\hline No. & $\begin{array}{l}\text { Tingkat Pengetahuan Ibu } \\
\text { tentang Tanda Bahaya } \\
\text { Kehamilan }\end{array}$ & Frekuensi & Prosentase (\%) \\
\hline $\mathbf{1}$ & Baik & 19 & $76 \%$ \\
$\mathbf{2 .}$ & Kurang & 6 & $24 \%$ \\
\hline Jumlah & 25 & $100 \%$ \\
\hline Sumber: Data Primer & $\begin{array}{l}\text { berpengetahuan baik tentang } \\
\text { tanda bahaya kehamilan yaitu } \\
\text { Berdasarkan Tabel 2, dapat }\end{array}$ & sebanyak 19 responden (76 \%)
\end{tabular}




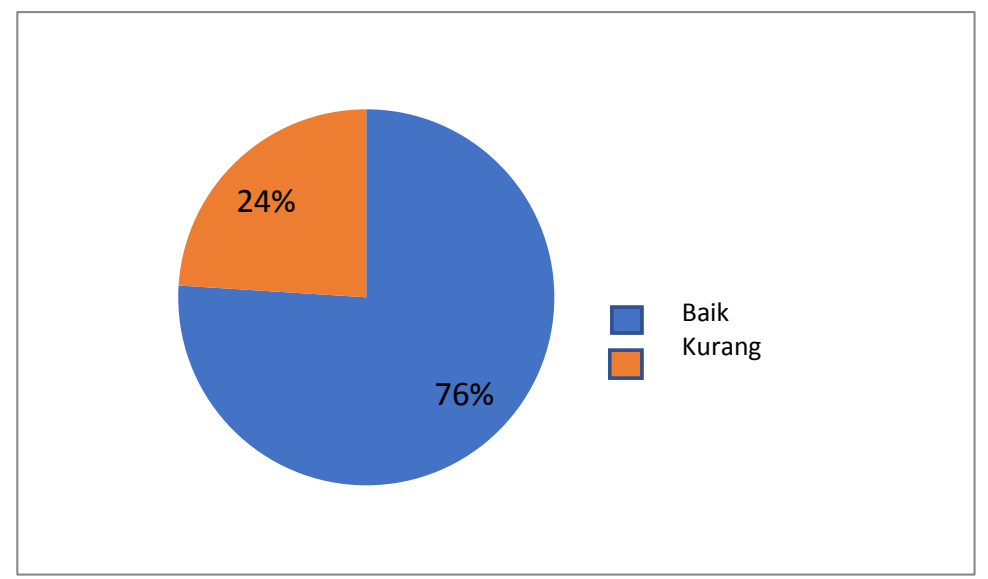

Gambar 2. Tingkat Pengetahuan Ibu tentang tanda Bahaya kehamilan

\section{Data Kejadian Resiko Tinggi}

Tabel 3. Distribusi Frekuensi berdasarkan kejadian resiko tinggi di BPS Ananda Desa Plosowahyu Kecamatan Lamongan Kabupaten Lamongan

\begin{tabular}{clcc}
\hline No. & Kejadian Resiko Tinggi & Frekuensi & Prosentase (\%) \\
\hline $\mathbf{1}$ & Ya & 5 & $20 \%$ \\
$\mathbf{2 .}$ & Tidak & 20 & $80 \%$ \\
\hline Jumlah & & 25 & $100 \%$ \\
\hline
\end{tabular}

Sumber: Data sekunder (1 Januari - 1 Mei 2018)

Berdasarkan Tabel 3, dapat diketahui bahwa mayoritas responden tidak mengalami resiko tinggi yaitu 20 responden atau $80 \%$.

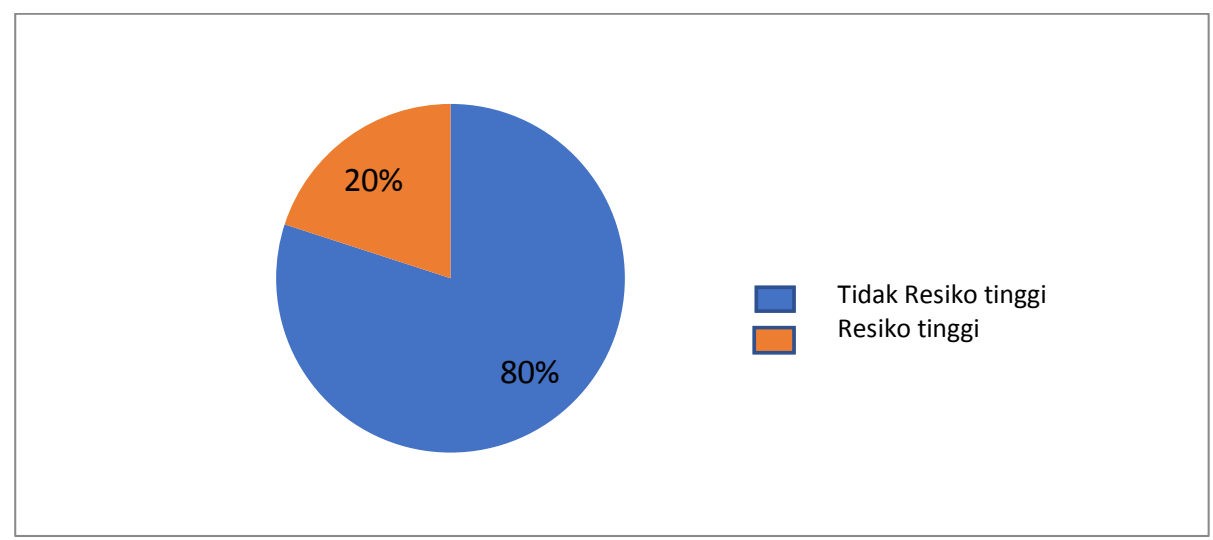

Gambar 3. Kejadian Resiko Tinggi

4. Data Tingkat Pengetahuan Ibu tentang Tanda Bahaya Kehamilan dengan Kejadian Resiko Tinggi.

Tabel 4. Distribusi Frekuensi berdasarkan Tingkat Pengetahuan Ibu tentang Tanda Bahaya Kehamilan dengan Kejadian Resiko Tinggi di BPS Ananda Desa Plosowahyu Kecamatan Lamongan Kabupaten Lamongan. 


\begin{tabular}{|c|c|c|c|c|c|c|}
\hline Pengetahuan & \multicolumn{4}{|c|}{$\begin{array}{l}\text { Kejadian Resiko Tinggi } \\
\end{array}$} & \multicolumn{2}{|c|}{ Total } \\
\hline & $\begin{array}{c}\text { Ya } \\
\text { Jumlah }\end{array}$ & $\%$ & $\begin{array}{c}\text { Tidak } \\
\text { Jumlah }\end{array}$ & $\%$ & Jumlah & $\%$ \\
\hline Baik & 1 & $5,3 \%$ & 18 & $94,7 \%$ & 19 & $76 \%$ \\
\hline Kurang & 4 & $66,7 \%$ & 2 & $33,3 \%$ & 6 & $24 \%$ \\
\hline Jumlah & 5 & $20 \%$ & 20 & $80 \%$ & 25 & $100 \%$ \\
\hline \multicolumn{3}{|c|}{$\mathrm{X} 2=10,746$} & & \multicolumn{3}{|c|}{$\mathrm{p}<0,005$} \\
\hline
\end{tabular}

Sumber: Data primer dan data sekunder.

Berdasarkan Tabel 4, menunjukkan bahwa mayoritas responden memiliki berpengetahuan kurang mengalami resiko tinggi yaitu 4 responden $(66,7 \%)$, dan responden yang berpengetahuan baik mayoritas tidak mengalami resiko tinggi yaitu 18 responden $(94,7 \%)$. Dari hasil uji chi-square didapatkan nilai $\chi 2$ hitung $=10,746>5,991$, sehingga $\mathrm{H} 0$ ditolak H1 diterima. Dengan demikian dapat disimpulkan bahwa ada hubungan antara pengetahuan tentang tanda bahaya kehamilan dengan kejadian resiko tinggi.

\section{PEMBAHASAN}

\section{Tingkat Pengetahuan Ibu tentang Tanda Bahaya Kehamilan} Hasil penelitian yang dilakukan terhadap 25 ibu hamil yang berada di BPS Ananda Desa Plosowahyu Kecamatan Lamongan Kabupaten Lamongan dapat diketahui mayoritas responden berpengetahuan baik tentang tanda bahaya kehamilan yaitu sebanyak 19 responden $(76 \%)$.

Notoadmodjo

mengatakan bahwa pengetahuan merupakan hasil tahu dan terjadi setelah orang melakukan penginderaan terhadap obyek tertentu, penginderaan terjadi melalui panca indra manusia yaitu indra penglihatan, pendengaran, penciuman, rasa dan raba. Menurut Wawan (2011) faktor-faktor yang mempengaruhi tingkat pengetahuan dibagi menjadi faktor internal (pendidikan, umur dan pekerjaan) dan faktor eksternal (lingkungan dan sosial budaya). Dalam penelitian ini tingkat pengetahuan ibu baik kemungkinan dapat disebabkan karena usia ibu hamil mayoritas adalah usia produktif yaitu 20-35. Pada usia 20-35 tahun seseorang akan lebih mudah menerima informasi dan mencari informasi, selain itu kemungkinan dapat disebabkan responden mayoritas berpendidikan menengah dan minoritas berpendidikan rendah. Semakin tinggi pendidikan seseorang akan mudah dalam pemahaman menerima informasi, dan dengan pendidikan yang kurang akan menghambat perkembangan pemikiran seseorang terhadap nilainilai yang baru diperkenalkan. Hal ini dapat ditarik kesimpulan sehingga usia 20-35 tahun serta berpendidikan semakin tinggi dapat mempengaruhi pengetahuan, daya tangkap dan pola pikirnya terakait dengan tanda-tanda bahaya kehamilan.

\section{Kejadian Resiko Tinggi}

Berdasarkan hasil penelitian menunjukkan bahwa sebagian besar ibu hamil tidak mengalami resiko tinggi yaitu 20 atau $(80,0 \%)$ dan yang tidak mengalami resiko tinggi sebagian besar adalah ibu hamil dengan pengetahuan baik tentang tanda bahaya kehamilan 
Menurut (Kemenkes RI, 2011) ada beberapa faktor yang dapat mempengaruhi terjadinya resiko tinggi yaitu 4 Terlalu. Melahirkan terlalu muda (dibawah 20 tahun), terlalu tua (diatas 35 tahun), terlalu dekat (jarak melahirkan kurang dari 2 tahun) dan terlalu banyak (lebih dari 4 kali). Sejalan menurut (Rinata, 2017) mengatakan bahwa usia ibu merupakan salah satu faktor yang dapat mempengaruhi terjadinya resiko tinggi pada kehamilan. Terjadinya peningkatan resiko tinggi adalah usia ibu hamil terlalu muda yaitu $<20$ tahun atau terlalu tua lebih dari 35 tahun. Faktor lain adalah paritas, grandemultipara dapat menyebabkan peningkatan terjadinya resiko tinggi. Dalam penelitian ini mayoritas usia ibu adalah usia produktif dengan paritas primi dan multi gravida, sejalan dengan teori yang ada sehingga hal ini dapat memungkinkan kejadian resiko tinggi pada ibu hamil rendah.

\section{Hubungan Tingkat \\ Pengetahuan Ibu hamil tentang tanda bahaya kehamilan dan Kejadian Resiko Tinggi}

Berdasarkan hasil penelitian menunjukkan bahwa mayoritas responden memiliki berpengetahuan kurang mengalami resiko tinggi yaitu 4 responden $(66,7 \%)$, dan responden yang berpengetahuan baik mayoritas tidak mengalami resiko tinggi yaitu 18 responden $(94,7 \%)$. Hasil uji chisquare didapatkan nilai $\chi 2$ hitung $=$ $10,746>5,991$, sehingga H0 ditolak H1 diterima. Dengan demikian dapat disimpulkan bahwa ada hubungan antara pengetahuan tentang tanda bahaya kehamilan dengan kejadian resiko tinggi.
Dalam bidang obstetri dan ginekologi terdapat potensi risiko, dimana suatu kehamilan selalu mempunyai risiko terjadinya komplikasi dalam kehamilan (Rinata, 2017). Deteksi dini tanda bahaya kehamilan dan faktor resiko merupakan kegiatan yang dilakukan untuk menemukan ibu hamil yang mempunyai tanda-tanda bahaya kehamilan. Kehamilan merupakan proses reproduksi yang normal tetapi dapat mempunyai resiko untuk terjadinya komplikasi. Untuk itu tanda bahaya perlu dideteksi sejak dini dan perlu penanganan yang adekuat sedini mungkin (Fajrin, 2017). Dengan adanya pengetahuan ibu yang mayoritas baik mengenai tanda-tanda bahaya kehamilan, ibu dapat mengetahui tanda-tanda bahaya kehamilan dan mampu mempertahankan kesehatan kehamilannya, karena apabila ibu menemukan salah satu tanda bahaya kehamilan yang terjadi pada dirinya ibu dapat segera mengenali sejak dini dan dapat segera memeriksakan kehamilannya lebih lanjut kepetugas kesehatan, sehingga kejadian resiko tinggi dapat dicegah atau bahkan segera diatasi. Untuk itu tanda bahaya kehamilan perlu dideteksi sedini mungkin dengan dasar pengetahuan ibu baik mengenai tanda-tanda bahaya kehamilan, melakukan pencegahan pro-aktif sejak awal kehamilan, selama kehamilan sampai menjelang persalinan yang dilakukan oleh tenaga kesehatan, bersama dengan ibu hamil, suami, serta keluarga dan perlu adanya penanganan yang adekuat terhadap kejadian resiko tinggi sebagai salah satu upaya untuk penurunan angka kematian ibu. 


\section{SIMPULAN}

1. Mayoritas memiliki pengetahuan ibu hamil baik tentang tanda bahaya kehamilan yaitu sebanyak 19 responden $(76 \%)$

2. Mayoritas tidak mengalami resiko tinggi yaitu sebanyak 20 responden $(80 \%)$.

3. Mayoritas responden memiliki berpengetahuan kurang mengalami resiko tinggi yaitu 4 responden $(66,7 \%)$, dan responden yang berpengetahuan baik mayoritas tidak mengalami resiko tinggi yaitu 18 responden (94,7\%). Dari hasil uji chi-square didapatkan Hasil uji chi-square didapatkan nilai $\chi 2$ hitung $=$ 10,746 > 5,991, sehingga $\mathrm{H} 0$ ditolak H1 diterima sehingga terdapat hubungan antara pengetahuan tentang tanda bahaya kehamilan dengan kejadian resiko tinggi

\section{SARAN}

1. Bagi petugas kesehatan

Diharapkan selalu memberikan KIE tentang tanda-tanda bahaya kehamilan serta melakukan skrining/deteksi dini adanya faktor resiko secara proaktif pada semua ibu hamil sejak awal hingga akhir kehamilan

2. Bagi institusi Pendidikan

Diharapkan hasil penelitian ini dapat dijadikan sebagai bahan literatur untuk dapat memberikan informasi tentang pengetahuan, pengembangan ilmu kesehatan serta sebagai penunjang keterampilan khususnya terkait pencegahan, pendeteksian dan penaganan terhadap kejadian resiko tinggi ibu hamil.

3. Bagi ibu hamil
Diharapkan dapat mengenali tanda bahaya kehamilan sehingga mampu melakukan deteksi dini terhadap terjadinya resiko tinggi

4. Bagi peneliti selanjutnya

Dapat mengembangkan penelitian dengan variabel yang berbeda yang bisa mempengaruhi terjadinya resiko tinggi pada ibu hamil.

\section{DAFTAR PUSTAKA}

Depkes Provinsi Jatim. 2017. Profil Kesehatan Provinsi Jawa Timur tahun 2016. http://www.depkes.go.id/re sources/download/profil/P ROFIL_KES_PROVINSI_ 2016/15_Jatim_2016.pdf

Depkes RI. 2015 .Kesehatan Dalam Kerangka Sustainable Development Goals (SDGs).http://www.pusat2. litbang.depkes.go.id/pusat 2_v1/wpcontent/uploads/2 015/12/SDGs-DitjenBGKIA.pdf

Dinkes Kabupaten Lamongan, 2016.

$$
\begin{aligned}
& \text { Profil Kesehatan } \\
& \text { Kabupaten Lamongan } \\
& \text { Tahun2016.http://www.de } \\
& \text { pkes.go.id/resources/down } \\
& \text { load/profil/PROFIL_KAB } \\
& \text { _KOTA_2016/3524_Jatim } \\
& \text { _Kab_Lamongan_2016.pd } \\
& \text { f }
\end{aligned}
$$

Kemenkes RI, 2014. Infodatin, Pusat dan Informasi Kementrian Kesehatan $R I$. http://www.depkes.go.id/re sources/download/pusdatin /infodatin/infodatinibu.pdf 
Kemenkes RI. 2011. Lima Strategi Operasional Turunkan Angka Kematian Ibu.. http://www.depkes.go.id/in dex. php?vw=2\&id=1387

Notoatmodjo, S. 2010. Promosi Kesehatan dan Ilmu Perilaku. Jakarta : Rineka. Cipta.

Fajrin, F. I. 2017. Asuhan Kehamilan. Jilid 1. Gresik: Graniti

Fajrin, F. I. (2017). Gambaran pengetahuan ibu hamil trimester iii tentang tandatanda bahaya kehamilan berdasarkan usia, pendidikan dan pekerjaan di BPS Sulastini A. Md. Keb. Jurnal kebidanan, 9(2), 7.

Rinata,Evi.2017. Prinsip Deteksi Dini Komplikasi Pada Ibu Hamil. http://eprints.umsida.ac.id/ 505/1/DETEKSI\%20DINI \%20KOMPLIKASI.pdf

Rochjati, Poedji., 2003. Skrining Antenatal Pada Ibu Hamil. Surabaya: Airlangga University

Wawan. 2011. Teori dan Pengukuran Pengetahuan, Sikap dan Perilaku Manusia, Yogyakarta : Nuha Medika

Yulanda, Desti. 2014. Hubungan Antara Pengetahuan Ibu Hamil Tentang Tanda Bahaya Kehamilan Dengan Sikap Deteksi Dini Komplikasi Kehamilan Di Puskesmas Kartasura Tahun 2014. http://jurnal.stikesmus.ac.i d/index.php/JKebIn/article /viewFile/104/101 